\title{
AN EXAMPLE OF A SELF-INSTRUCTIONAL TEACHING UNIT FOR NURSING STUDENTS
}

\section{T.M. BENDILE}

\section{OPSOMMING}

Die ontwerp van onderrigeenhede waarin die onderrigmetodes met die doelstellings ooreenkom en waarin hoër vlakke van denke by die student gestimuleer word, word aan die hand van 'n voorbeeld, oor motivering en verdedigingsmeganismes, geïllustreer.

\section{INTRODUCTION}

Designing effective teaching units is a very important part of the work of the tutor. As part of a course in curriculum development at the University of the Orange Free State, tutors are given practice in this skill. Much attention is given to varying the teaching methods and adapting them according to the unit objectives, which in turn arise from a task analysis. The emphasis of the teaching methods is also on developing higher levels of thinking in the student. An example of such a teaching unit is presented here

\section{TEACHING UNIT}

\section{COURSE}

Introductory psychology

\section{TARGET GROUP}

Second year students: Diploma in General Nursing

\section{COURSE OBJECTIVE}

Students will be able to understand human behaviour in health and in illness, and be able to use this knowledge in the care of patients as individuals and in groups.

\section{TITLE}

Human motivation and ego-defence mechanisms, and their application to nursing care.

\section{SPECIFIC OBJECTIVES}

- Define motivation and identify the biological and the psycho-social forms of motives.

- Define ego-defence mechanism and describe the relationship between this and motivation.

- Identify, from a given description of a patient's behaviour, his felt needs, and plan for appropriate nursing care.

- Describe, in your own words in writing, without the help of your prescribed sources, the defensive behavior characteristics of each of the following Mechanisms:

regression

rationalisation

projection

displacement identification sublimation

- Identify in yourself (or in others) a lack of motivation and analyse the possible causes thereof.

- Identify situations in which the patient demonstrates excessive use of one or two defences and plan for the appropriate nursing care.

- Identify your own habitual defence mechanisms.

\section{RATIONALE}

All behaviour is directed towards the satisfaction of a person's needs and the fulfilment of his aspirations. Nursing involves mainly helping the patient to meet his needs. The nurse must have insight into the processes involved in motivation such as why a lonely person will have difficulty in respecting himself.

Inability to handle his situation adequately affects the patient's self-image making him anxious and causing him to adopt one or other ego-defence mechanism. This is a normal reaction, but one needs to know when the patient is using defences excessively because this makes him rigid and unopen to the care planned for him.

\section{ENTERING BEHAVIOUR}

Before the student proceeds with the learning, she must have acquired knowledge concerning

- the concept psychology and how it is applied to nursing practice;

- the organic structure of the body in relation to emotion;

- the effect of hypothalamic stimulation on the body, and its influence on behaviour. 
Concept psychology and how it is applied to nursing practice

Psychology Scientific study of behaviour and experience.

dge about reality is gained

Science A method of study by which knowledge about reality is gained largely under controlled conditions rather than by casual observation.

Behaviour All observable (overt) and non-observable (covert) reactions to stimulation.

Experience Mental processes occuring within the individual as a result of exposure to a situation.

Application The extent to which the nurse-practitioner is able to use the knowledge gained from psychology in her relationships with others and in patient intervention.

\section{The organic structure of the body in relation to emotion}

The autonomic nervous system

The parasympathetic system generally has a soothing effect on body tissues.

The sympathetic system has a stimulating effect, its output being directly related to the energy levels needed by the body.

\section{The hypothalamus}

Is the main seat of emotional expression.

Is closely associated with the autonomic nervous system.

Is sensitive to conditions of stress and operates through the sympathetic stimulation to restore body equilibrium.

The endocrine system

Secretes special chemicals (hormones) which influence the behavioural reactions' of the individual, such as energy levels, and reaction-time.

\section{Effects of hypothalamic stimulation on the body and its influence on behaviour}

See diagram 1.

The student who has not mastered the above concepts must do so before proceeding with the rest of the unit.

\section{Consult:}

1. Fisher, E.E. Psychology for Nurses and the Health Team. Juta \& Company, Cape Town, 1981 4th Ed (pages 2-6.)

2. McNaught, A.B. Callander, R Nurses' illustrated physiology E. \& S. Livingstone London 1971 2nd Ed. (pages: 94 and 150)

The estimated study time for this unit is one week

\section{EVALUATION PLAN}

\section{Progress-test}

A progress test is included by which the student must test herself. The answers are provided at the end of this
Diagram 1. The effects of hypothalamic stimulation on the body and its influence on behaviour.

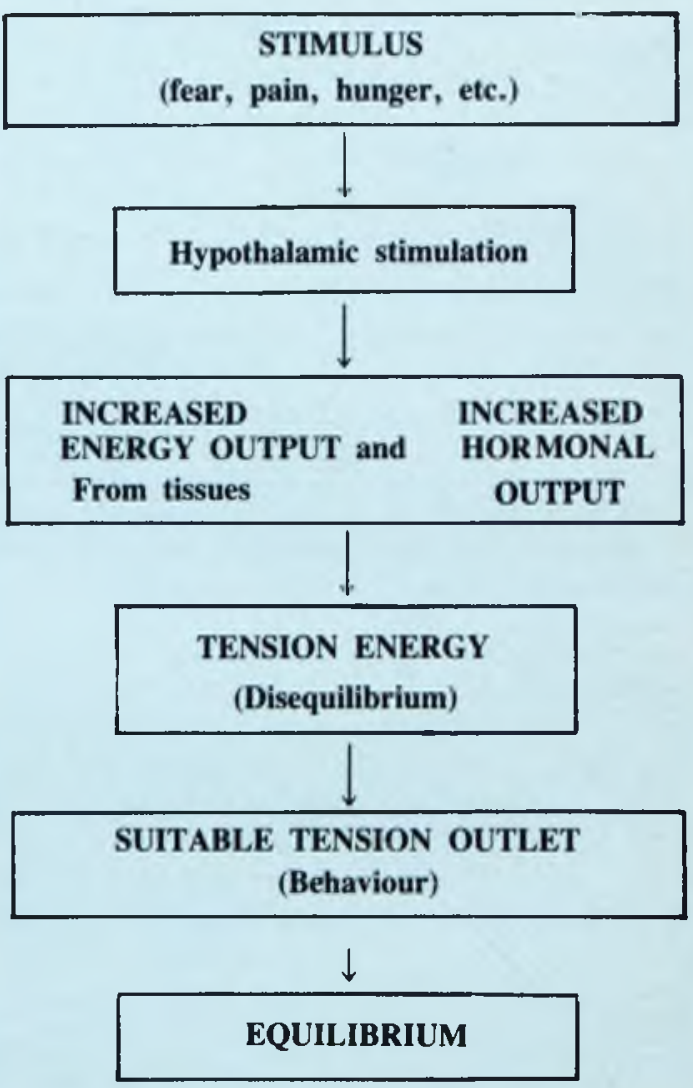

unit. The student must obtain a $100 \%$ score and if not, must study the unit again and re-test herself until at least $100 \%$ accurate. The student must first answer the questions and then give herself a score against the correct answers provided.

\section{Final test}

A final test will be given at the end of the week, on a given date. The student will be tested on all the work covered in the unit. The questions will, by and large, be on application of the concepts motivation and ego defence mechanisms to the planning of care for a (hypothetical) patient.

\section{TASK DESCRIPTION AND ANALYSIS}

\section{Hierarchy of human needs (Maslow)}

Maslow's hierarchy of human needs must be seen in relation to patient care. See flow-diagram 1.

\section{Relationship between motivation, anxiety and ego-defence mechanisms}

See flow-diagram 2

\section{Identifying motives underlying behaviour and planning care}

Possible motives underlying the patient's behaviour must be identified and the necessary care planned. See flow-diagram 3. 
Flow-diagram 1: Hierarchy of Human Needs (Maslow)

(5) Self-actualisation achievement; attainment of goals; competence

(4) Self-esteem respect; recognition, honour, prestige, independence.

(3) Belonging needs affection; friendship acceptance; interperso nal relationships.

(2) Safety needs protection; familiar environment; non-fear provoking situations.

(1) Biological needs air, food, water, sleep exercise, elimination etc.
Dominant in the con-

valescing patient.

Dominant in the loss of

status for the hospital-

ised patient; exposure

to medical treatments etc.

Strongly felt by children

in separating states, by

the neglected patient and

the homeless patient.

Become dominant in newly

admitted patients; in

disasters etc.

-Aroused first and become dominant if not satisfied -If adequately met needs of the higher levels are felt

-Most urgent in states of shock due to dehydration or blood loss, and in respiratory distress.
Flow-diagram 2: Relationship between motivation, anxiety and ego-defence mechanisms.

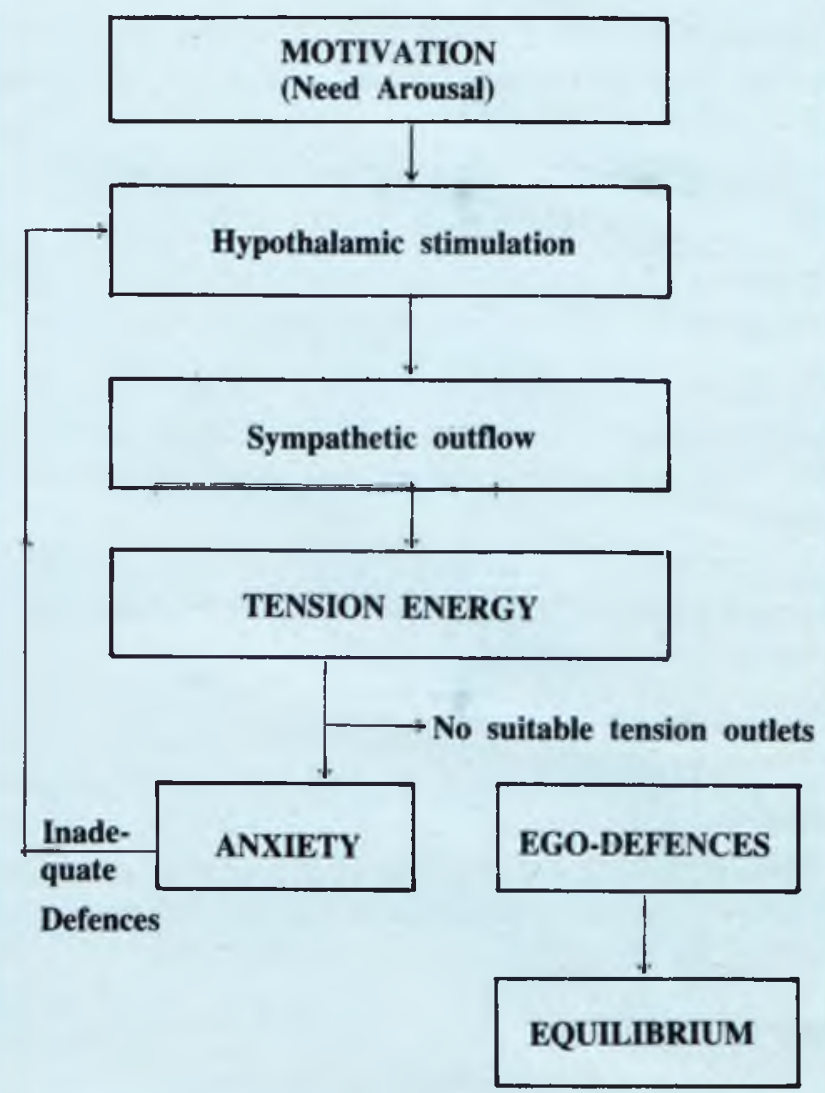

Higher level needs arise when lower ones are satisfied.

Regression to lower needs occurs when higher needs are frustrated.

\section{Flow-diagram 3: Identifying motives underlying behaviour and planning care}

Possible motives underlying the behaviour of an adult patient who refuses hospital treatment and wishes to sign the Refusal of Hospital Treatment form, and the care which can be provided

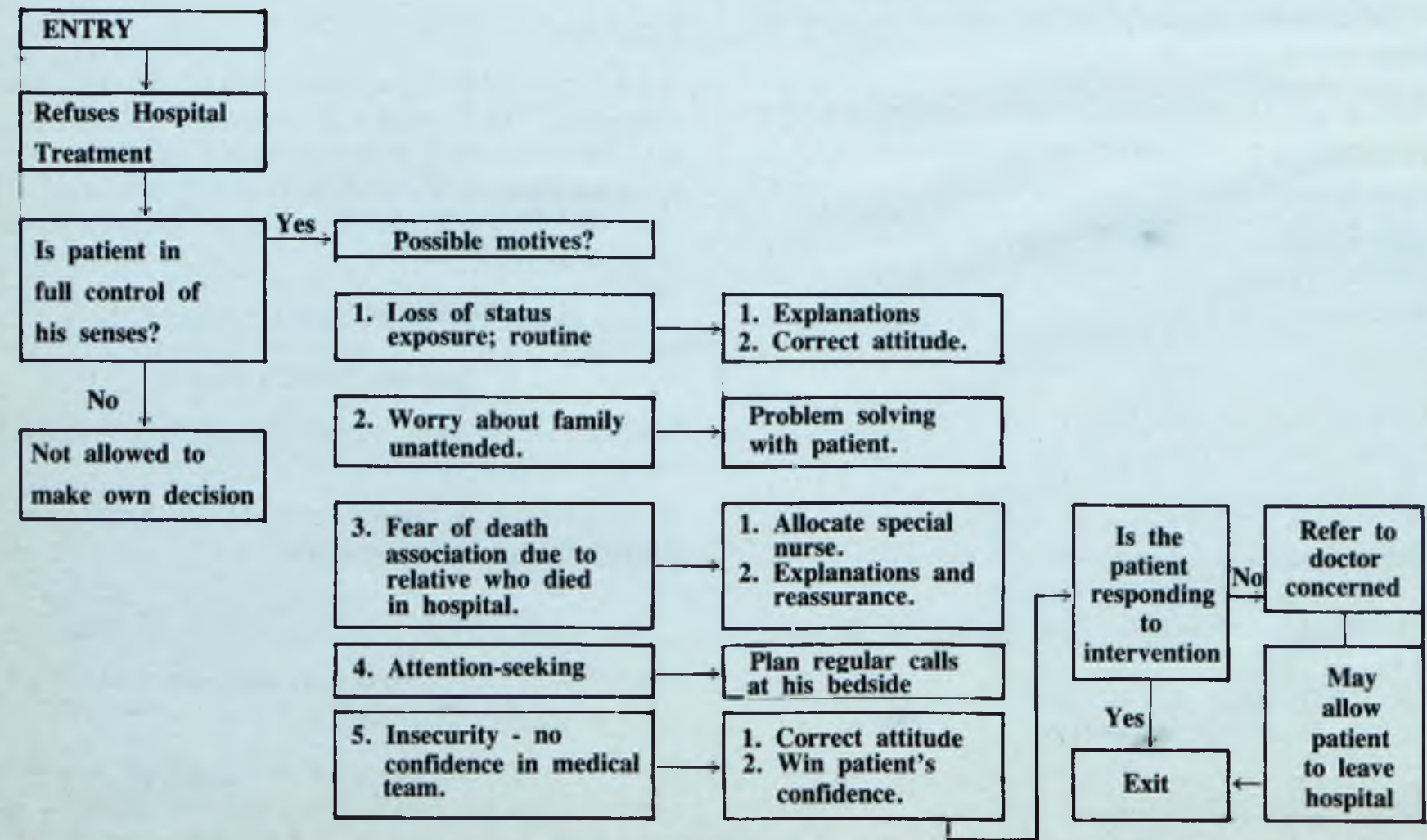




\section{Concepts to be learned}

\section{On motivation}

biological drives

emotional drives

psycho-social needs

hierarchy of human needs (Maslow's theory)

unconscious motivation.

\section{On ego-defence mechanisms}

the concept ego-defence and the processes involved displacement

identification

projection

rationalisation

regression

sublimation

\section{Principles to be learned}

On motivation

* All behaviour is motivated, that is based on needarousal.

* Much of our behaviour has unconscious motivation.

* Need-arousal puts the individual in a state of tension and readiness to meet the felt need.

* Needs that cannot be met puts the individual in a state of disequilibrium or anxiety.

* Motivation is inferred from the individual's behav- iour and, in the case of the patient, assists in the planning of nursing care.

\section{On ego-defence mechanisms}

* In most people anxiety is dealt with by the adoption of appropriate ego-defence mechanisms.

* Inability to cope imposed by illness renders the patient more predisposed to anxiety, and makes him adopt defensive behaviour.

* Overuse of one or two ego-defence mechanisms makes the individual rigid and it is difficult for him to enter into meaningful relationships with others.

\section{Skills}

The nurse is able to

identify the patient's needs and compile a comprehensive care plan to meet those needs;

create situations that encourage a hopeless patient to identify with, and therefore gain support from, other patients who are facing illness bravely;

create a ward atmosphere which provides tensionoutlets for the patients, for example suitable indoorgames and cheerful conversation;

recognise, in the patients' behaviour, excessive use of defences, or inability to formulate defences, and plan for the necessary support systems.

\section{PRESENTATION TECHNIQUE}

The student is given the specific objectives, the entering behaviour and the task description with the following instructions.

1. Study the diagram depicting Maslow's hierrarchy of needs (flow diagram 1) and test yourself with the few questions below.

1. Define the concept hierarchy of needs. Confine your answer to about 20 words.

\section{ANSWER:}

The lower (biological)needs dominate and the higher needs emerge only when the lower ones have been met.

2. When the needs in level 1 are unsatisfied, how can you explain the patient's condition in a few words with regard to the higher level needs?

\section{ANSWER:}

All other higher level needs recede. For example, if there is no water, nothing else matters.

3. Name any three ways to help the patient fulfil the needs in level 2.
ANSWER:
a) Teach him how to use hospital equipment (eli- minate anxiety)
b) Show skill when carrying out procedures on him.
c) Keep patient and ward environment very clean.
d) Assist him with domestic problems.

If not satisfied with your own answers, study flowdiagram 1 again.

2. Study the flow-diagrams 2 and 3 .

Attend the film Anger at work which demonstrates a case of displacement of anger.

(Running time $=191 / 2$ minutes.)

$$
\text { OR }
$$

The film Neurotic Behaviour which includes illustrations of some classical ego-defence mechanisms.

(Running time $=19$ minutes)

Attend the film Angry Boy which illustrates how unconscious motivation affects the behaviour of both children and adults.

(Running time $=31$ minutes)

Study ego-defence mechanisms in Vlok (1973: 327341 ); or any other relevant literature. 
(The college time-table on FILMS shows students when and where the above films will be showing.)

\section{PROCEED TO TEST YOURSELF WITH THE FOL- LOWING QUESTIONS:}

(First write down your own answer before consulting the one provided. Study again the areas in which you gave a wrong answer.)

1. Define the concept motivation and support your definition with a suitable example.

\section{ANSWER:}

Motivation is the arousal of an internal stimulus, which may be conscious or unconscious, which energises the individual and makes him behave in a certain way.

Example: A thirsty person is motivated to drink water.

2. Describe, in a paragraph of not more than 120 words, the process by which ego-defence mechanisms occur.

\section{ANSWER:}

A person meets a situation which he cannot handle, experiences threats in his environment or encounters any other impediment which makes him uncomfortable. His energy levels rise to help him overcome the handicap by direct means (e.g. fight or flight) and this makes him tense. If no suitable means are available, he becomes anxious. Because anxiety cannot be relieved by physical fear-reducing measures, the person unconsciously develops psychological mechanisms which bury his anxiety in unconsciousness, and make him comfortable with himself again.

These mechanisms are ego-defensive in that they prevent the lowering of the person's self-esteem and prevent disintegration of his person.
3. For each of the behaviours described here, identify the ego-defence mechanism employed.

3.1. The patient states that she could not seek medical advice early because she had nobody to remain with her children when she was, in fact, afraid of the possible outcome of the consultation.

3.2. Nurse Judy is concerned about a patient in her ward who appears lonely and never seems to get visitors. So, whenever nurse Judy gets the chance, she spends a few minutes engaging the patient in conversation.

3.3 Peter is a sixteen-year-old boy. His parents often scold him for his poor performance at school. Peter spends most of his time playing football. His club-members call him Pele after the Brazilian football star whose style and mannerisms Peter has adopted.

3.4 A student constantly accuses her group-mates of untidiness and says they are always throwing tissues about. But looking at her own behaviour one can say that hers is worse than theirs.

\section{ANSWER:}

$$
\begin{aligned}
& \text { 3.1. - Rationalisation } \\
& \text { 3.2. - Identification } \\
& \text { 3.3. - Identification } \\
& \text { 3.4. - Projection }
\end{aligned}
$$

4. Name the steps that must be covered in the process of providing nursing care for the patients.

\section{ANSWER:}

1. Assessment of patient

- general condition

- prevailing needs.

2. Devise a plan to provide the patients' needs.

3. Use the plan and observe patients' response to care.

4. Evaluate patients' condition and decide whether further intervention is necessary.

\section{PROGRESS-TEST}

The student must obtain full marks in this test, if not she must follow the instructions at the end of this test. It is in the student's own interest to do so.

\section{Instructions:}

- Write down in your exercise book the answer(s) to each item without looking at the answers which are provided at the back of the unit.

- Do not consult your references while answering the questions.

\section{Item 1}

Indicate $(\checkmark)$ whether the following statements are true or false:-

1. The nurse can help to reduce the patient's anxiety by leaving the patient to sort out things for himself.

\section{TRUE/FALSE}

2. The so-called difficult patient may be motivated to escape from pain.

\section{TRUE/FALSE}

3. The patient who complains that nobody loves him 
and that he feels alone in the world can be helped to overcome this feeling by assuring him that the doctor attending him is very experienced in his job.

\section{TRUE/FALSE}

4. To make the patient develop the urge to get well the nurse should use threats to force him to co-operate in his own treatment.

\section{TRUE/FALSE}

5. The patient who is constantly seeking the attention of the nurse for no apparent reason can be said to be using the mechanism of regression.

\section{TRUE/FALSE}

\section{Item 2}

Indicate with a ring around the alternative which best describes the behaviour:-

1. If the patient behaves rudely towards the nursing staff as a result of his anxiety about his illness, which of the following ego-defences would suit this behaviour?
1.1. Sublimation
1.2. Projection
1.3. Displacement
1.4. None of the above

2. When a person is very critical of others and always finding fault, it can be assumed that he is using the mechanism of:-

2.1. Projection

2.2. Aggression

2.3. Sublimation

2.4. Displacement

3. The mother who punishes her child and justifies her action by saying that it is for the child's own good whereas she may in fact be relieving her own anger is using the mechanism of:

\subsection{Displacement \\ 3.2. Sublimation \\ 3.3. Projection \\ 3.4. Rationalisation}

4. When an elderly patient shows regressive behaviour by soiling her bed-linen and refusing to use the bedpan, the nursing staff should:

4.1. Tell the patient that the nurses have a big workload, and unless she behaves they will ask the doctor to discharge her.

4.2. Not scold her at all.

4.3. Give her love and attention

4.4. Wash the patient with cold water so that she will not soil her bed again.

4.5. Let the patient do as much for herself as possible to prevent total dependence.

4.6. $(4.2 ; 4.3$; and 4.5$)$

4.7. $(4.3 ; 4.5)$

4.8. All of the above.

5. To plan for nursing care, the nurse must assess the needs of the patient. This can be done by:

5.1. Asking the patient how he feels.

5.2. Telling the patient that you will not help him unless he tells you the truth.

5.3. Observing the behaviour of the patient.

5.4. Examining the patient physically to determine his nutritional state.

5.5. $(5.2 ; 5.4$.

5.6. All of the above

5.7. $(5.1 ; 5.3 ; 5.4$.

\section{Item 3}

Fill in the missing words. Do not rewrite the whole sentence; simply write down the word(s):

1. Ego-defence mechanisms are behaviour patterns used to reduce or remove ... . which cannot be handled by physical means.

2. The ego-defence mechanisms make the individual comfortable with himself and better able to adapt to the requirements of society. Therefore, they play an important part in interpersonal. ...

3. To motivate a person is to ... needs in him, and we can see whether or not a person is motivated by his ...

4. When a patient is dyspnoeic, he becomes restless and fidgety, refuses to co-operate with the nurse who comes to change her bed-linen because at this moment the .... is dominant and the patient cannot be motivated to do anything else.

\section{FINAL INSTRUCTIONS:}

1. Determine your performance:

.... out of 15

2. Full marks? You have mastered the task! Very good.

3. Any mistakes made require you to refer back to the Presentation technique and study the areas in which your answers were wrong. Then re-answer the questions which were answered incorrectly until you have all the answers correct.

\section{ANSWERS TO PROGRESS-TEST}

Item 1

$\begin{array}{lr}\text { Number } & \text { Answer } \\ 1 . & \text { False } \\ 2 . & \text { True } \\ \text { 3. } & \text { False } \\ \text { 4. } & \text { False } \\ \text { 5. } & \text { True }\end{array}$

Item 3

$\begin{array}{lr}\text { Number } & \text { Answer } \\ 1 . & \text { anxiety } \\ 2 . & \text { relations } \\ 3 . & \text { arouse; behaviour } \\ 4 . & \text { biological (physical) need. }\end{array}$

\section{SOURCES}

1. Altschul, A. Psychology for nurses Bailliere Tindall. London 1975 4th Ed.

2. Fisher, E.E. Psychology for nurses and the health team Juta \& Company Cape Town 1981 4th Ed

3. McNaught, A.B.; Callander, R. Nurses illustrated physiology E. \& S. LIVINGSTONE London 1971 2nd Ed.

4. Vlok, Manual of Advanced Nursing Juta \& company Johannesburg. 